\title{
Communication Media Technology And Social Harmony Construction In The Era Of Society 5.0 A Critical View
}

\author{
$1{ }^{\text {st }}$ Burhan Bungin, $2{ }^{\text {nd }}$ Hilda Yunita Wono, $3{ }^{\text {rd }}$ Ergita Jeny Ardaneshwari \\ School of Communication Science and Media Businesses \\ University of Ciputra Surabaya \\ Surabaya, Indonesia \\ buhan.bungin@ciputra.ac.id, hlda.yunita@ciputra.ac.id, eardaneshwari@student.ciputra.ac.id
}

\begin{abstract}
The current media communication technology is growing into an inevitability. This medium can make a world as big as an egg, and it can similarly build a harmony based on its will. The study revealed how communication media technologies are able to build a reality of harmony in society. The study employed a qualitative approach with a post-positivistic paradigm. The research took 5 informants and interviewed them. The results of the study, (1) communication media technology became the main key formed society 5.0. (2) The development of social media in various platforms and with all its advantages caused the mass media mind stream fall one by one. (3) Communication media technology into a medium can bring the far and away close, or in other words create harmony that is switched. (4) Communication media technology has an impact on the occurrence of hoaxes that are actually enemies of the state.
\end{abstract}

Keywords:Communication Media Technology, Society 5.0, The social construction of reality, Harmony, Hoax

\section{INTRODUCTION}

Society 5.0 USES industrial 4.0 technologies where information technologies as a telematic core plays a crucial role in every step of society's social life. The use of digital transformation technologies, the development of big data technologies, the Internet of things (IOT), artificial intelligence (AI), the more flexible use of digital currency, allowing people to become freer, and go about their daily routine of living without the limitations of space and time that have been the main obstacle.

At the same time, social changes follow the breakdown in communications technology, communication media and the rest of the technology associated with it. An important part of human social life is that social reality is also transformed and even perish as these technologies begin to fill the social fabric of society.

In some societies the social realities of the cultural elements have changed completely, leaving their substance behind. One that marks this change is the reality of human relationships, between groups, between societies, and even the reality of human relationships with the universe. In relation to human relationships, whether personal, group and community, there is a very fundamental change, as communication media has taken over the important sides of the relationship and leaves a negative effect on the next social life.

In the critical view of the theory, the impact produced by the media was not a singular effect, but a mutual process (Kearney, 1994). As if society is magnetized, media forces have given choices that society cannot make. This condition is as defined by Karl Marx with alien diction. Karl Marx (1927) established the crush-theory of alienation in economic and 1844 manuscripts, that god's supernatural ideas have alienated the characteristics of human life. In other words, humans have invented the same idea of religion and religion that alienates humans. Karl Marx's thesis is evident now that communication technology is both human and human creation and alien to it.
In the society 5.0 era, society was driven by rapid technological advances to increase in the 4.0 industrial revolution, which is a cloud-based generation of storage Internet machines. This "sky" technology causes the ability of human technology to mirror the way god has kept the "pahala-crimes files" of mankind until doomsday. These cloud machines cause man to create easily big data and with big data technology human data will more freely develop communication technologies to create technologies that enable human activity to be highly efficient.

The question is, is there still a reality in society 5.0 when technology has taken over some or all sides of human life. Is there any left over from the old social reality awakened through the process of years of social construction, is there a new social reality already awake? And how do mass media (communications) build new social realities and create harmony in our current social lives?

\section{RESEARCH METHODS}

This research uses the paradigm of post-positivism, with simple research design method. The use of the postpositivism paradigm as referred to by Creswell (2018), when he explained about combined research that this research combines quantitative approach and qualitative approach. Researchers started the research deductively and eventually the data was managed qualitatively. When Creswell (2018) explains combined research, Creswell uses the paradigm of post-positivism as his basis for thinking.

Burhan (2020) explains simple research design which is very similar to combined research method, is the most appropriate choice in research with a paradigm of postpositivism. Thus, this research uses the paradigm of postpositivism with simple research design method.

Researchers use simple research design method steps as follows: (1) Social Context and Research Question, (2) Literature Review, (3) Research Methods and Data Collection, (4) Data Analysis, (5) Reporting. 
In the data collection researchers interviewed 5 (five) informants as a source of information in this study, selected purposively, where researchers have clearly identified the capacity of informants as a data source that has the ability to answer the questions of researchers. These five informants as described in the table below.

Table 1. Informant Research and Capacity as An Informant

\begin{tabular}{|c|c|c|}
\hline No. & Gender & Capacity \\
\hline Informant 1 & Man & Communication media experts \\
\hline Informant 2 & Man & Communication media experts \\
\hline Informant 3 & Woman & $\begin{array}{l}\text { Lecturer in communication } \\
\text { media technology }\end{array}$ \\
\hline Informant 4 & Woman & Social media practitioners \\
\hline Informant 5 & Man & Social media practitioners \\
\hline
\end{tabular}

Interviews conducted between January 2021 and March 2021, implemented in several places in Surabaya, namely in cafes and in city parks, so as to create calm conditions and protected the privacy of informants and researchers. Thus the informant-researcher can express his questions and opinions clearly, without being in penetration environment and forced impressions.

Research results in the form of diary, then made interview transcripts. The research analyzed the interview group manually using coding, categorization, themes and memos (Saldana, 2016). The final stage of the study writes the results of the study based on the results of the analysis of the data.

\section{RESULT AND ANALYSIS}

\subsection{Social Reality Society 5.0}

Industrial Revolution (4.0) one figure smaller than the development of society (5.0), this is because human society first existed and developed, only then were born various technologies in that era. Technology was created by humans for the benefit of human society, therefore society first developed and then developed industries.

In Society 5.0, various human roles are replaced by technology, such as the role of drones for logistics and transportation issues more prominently, as well as household appliances will use artificial intelligence technology, the demands of medical care needs are getting higher by using robots. Smart work will also be a model of work in various industries such as hotels, hospitals, households and so on, so robot become co-workers or human servants even become "wives or husbands" in our homes. Wider use of services from cloud services will facilitate and delight users in various business areas such as The Accounting Cloud, Production management, Sales management. New actors will come in logistics and transportation such as autonomous vehicles, as in sci-fi films, become a symbol technology of the future. All of this happens because there is Big Data, the Internet of Things (IoT) and Artificial Intelligence (AI).

Big Data is a term that describes large volumes of data stored in cloud machines, both structured and unstructured data. The three strengths of Big Data are that the volume of data is collected from various sources such as business data, social media data and information mining machines such as
Google, Baidu, Bing, Yahoo, Bingdex, Naver, Ask, Dogpile, DDG, Aol and so on. In addition, Big Data has a speed created from RFID tags (smart sensors) so that it has real time capabilities. Most importantly Big Data could collect data in a variety of different formats so that it can be collected from different sources, ranging from structured, numerical data in traditional databases, structured text document data, email, video, audio, financial transactions and others. In addition to these three important parts of Big Data, Big Data researchers also add important parts of Big Data such as variability and complexity.

The development of this Big Data machine caused two other technologies to also develop in parallel, namely, Internet of Things (IoT) and Artificial Intelligence (AI). Big Data collected by IoT will be converted into a new type of intelligence by AI and will reach every corner of people's lives.

IoT has no definitive definition, as this concept continues to always evolve in every community activity. IoT is a concept in which an object can transfer data over a network without requiring human-to-human or human-tocomputer interaction. IoT is also evolving from the convergence of wireless technology, internet, and microelectromechanical systems (MEMS). So that a technology can no longer be recognized based on its nature and initial function, even we can no longer give him a definite name. For example, we used to be able to use a mobile phone with the name of a mobile phone (HP), but nowadays this technology is no longer appropriate we call hp even smartphones.

Artificial intelligence (AI), the ability of a digital computer or computer-controlled robot to perform tasks commonly associated with intelligent beings. The term is often applied to system development projects endowed with characteristics of human intellectual processes, such as the ability to reason, discover meaning, generalize, or learn from past experiences (Copland, 2020). This AI is designed to replace the role of humans in some social functions that are later integrated into social systems in real life or cybercommunity like what is currently being developed by some countries, such as Japan.

Social life is undergoing a never-cease change. These days it is just the process of putting together a social construct that increasingly forms an image from a vague and abstract image into a more concrete image building. From one social building to another, naturally based on its social laws.

The social world is not a building without meaning, not empty spaces, not a process that is born and then simply disappeared, but the momentum created from the very complex social interactions that will produce a reality. A momentum will result in other social processes, so on. A small reality that occurs today may reproduce a large social building event in the future. But most of the big social realities, too, will disappear with the passage of time in the future. Most importantly, those events (realities) move based on social law to create other events (realities) in the future (Burhan, 2018).

Similarly, the technology institutions in Society 5.0 experienced that the image of technology is constructed by 
the agent of its creator, then born into the reality of the moment and will disappear at another time following the direction in which the image of technology is constructed, so that the reality of technology imagery will come and go in the spaces of time it has.

\subsection{The Demises of the Mass Media}

McQuail (1992) has long said that mass death is everchanging, without a definite shape. Mass is a formless collectivity and does not recognize the existence of individuality. Thus, the mass media is something that always does not have the strength to survive in a segment that can be expected by media owners, that they will be able to sell media products to groups of people as regular customers of their media.

Managing Editor of the New York Times, Jill Abramson reported Tempo August 16, 2013, said, in early June 2009 then already about 40 newspapers in America are facing bankruptcy. Most print media are bankrupt because advertisers prefer to place ads in online media rather than print media. Data KPCB (Kleiner Perkins Caufield Byers) in 2014, it showed, the decrease in the number of advertisers using print media in America is indeed alarming. On the contrary, television still dominates and is followed by online media whose traffic continues to grow (Event, 2019).

Print media faced a difficult time, when advertisers began to leave it on the assumption that customers were more interested in watching television or using social media in interacting or searching for news. Data shows that the Internet, TV and social media are the most numerous media (82\%-94\%) women are used to search for news, while (74\%-90\%) are used by men to search for news. While print media such as magazines, newspapers and others only get $2 \%-17 \%$, which is the lowest portion (Heygoblog, 2016). This data at the same time shows that the media of the time such as print media, radio has lost its mass, except television that can still survive sometime in the future. All news accessed by the public is obtained from individual media such as handphone and internet, this fact also shows the demission of mass media.

In recent days television began to be agitated because the bankruptcy of print media began to hit television. Television viewers began to leave television and switched to Youtube. Televisions will one day collapse not because of the fight of fellow television industry players, but from a new application called Youtube. In America, the number of television viewers among young people and adolescents decreased drastically, as they watched More Youtube. So, if the television industry does not immediately innovate then tomorrow, we will see television fall one by one. The nature of television that relies on mass and real time has ended because television viewers today want more individual shows in hand and want time to control watching by viewers rather than by television.

\subsection{Swapped harmony}

Berger and Thomas Luckmann (1967) are classical phenomenologists, they see the social process as evolutionary, the transformation of information in the social process takes place from person to person linearly. Berger and Luckmann, not even at all see that one-day technology (communication) will take over the role of humans in social processes. Basic Social when Berger and Luckmann made their thesis on the social construction of reality, was in the semi-modern era and dominated by technology with the hallmarks of the Industrial Revolution 3.0 era. The hallmarks of American social relations in this era run directly between people per person.

So, what really took place in this era of Society 5.0 and we look back at what happened in the Industrial revolution 4.0 that really the main trend of this era is the merger of automation technology with cyber technology. These cyber machines have evolved in all aspects of life like mushrooms covering all aspects of life related to important functions in people's lives, such as banking, education, state, transportation, social relations, science and so on. But there are also related things that are not important, but entertaining and so on, for example FaceApp, is one that is not important but becomes important when it becomes a trending topic on social media.

So, not only because FaceApp is an application that can change the reality of the face, but more than that, a reality in an instant can be created by the engine-masin this application by using the resources available in IoT, Big Data or AI. On the other hand, if we look at the output of these applications, let's just say FaceApp, MSQRD, Face Swap Live, Snapchat, Pace Swap Booth, AgingBooth, Pace Swap, MixBooth, Face Swap-Axhunter, Face Changer, Face Switch, Face Changer Video, Multi Face Blender, Change face, Face Swap-Wombatica Software, Face Swap Live-Android, is something that can actually eliminate reality, or even make reality as something created or created by the machines.

The question is, does reality really still exist? or it has been gone in the sense that reality actually exists solely because technology was created, beyond that there really is no reality. Durkheim (Ritzer and Stapnisky, 2017) say social reality is something that is material or observable as well as something that is nonmaterial or cannot be observed. But both realities are in observation as well as in consciousness. In other words, social reality is a reality that physically exists and exists also because of consciousness. Society 5.0 uses technology that can change social reality into consciousness but does not exist physically, or vice versa. The applications mentioned above, can convert objects into real image reality that is not real (does not exist) but can be observed as the reality of imagery that actually exists or even vice versa.

The social reality that Berger and Luckmann (1967) are said to be the product of social construction, is the result of a complex social process in simultaneous social processes and lasted many years, becoming very simple in Society 5.0 , because the social construction process has been replaced by the construction of reality imagery applications made by machines internet-social media in an instant, make the process of social construction of social reality technology very quickly awakened, quickly existed, then meaningless and then nothing. This is the future of social reality in the Era of Society 5.0, as something that exists and is created by the machines of internet-social media. 
The birth of old reality through social construction, giving birth to social harmony in people's lives. Social reality is born into an evolutionary social product based on the wishes of the surrounding community. The construction of family reality is the harmony of sexual needs and male responsibility towards women. The reality of the market is the harmony of demand and supply. Constructed reality of democracy is the harmony of state life. The reality of safety on the road is the harmony of traffic obedience. The reality of a beautiful environment is the harmony of man and his environment, and so on. These social harmonies were formed over the years through social construction.

When technology can create that reality revolutionary, then harmony becomes present but does not last long or does not even exist. The reality of communication media often exists and just disappears, even that reality exists but creates conflict in society. The case of EviApita Maya "CalegFotoTerlaluCantik" is an example of the loss of harmony in the reality of social media communication. So does the reality of social media spawning media crime everywhere, the birth of infidelity, a violation of social ethics, are examples of harmony that are confused in our social lives.

But not least also the reality of social media communication that is constructed beneficial for human social life, such as social media as the reality of learning media, the reality of social media build friendship, and so on. However, in general communication media becomes an absurd medium such as communication media "find the lost and eliminate the existing", "bring the far and keep the close". In this kind of reality, social harmony has been switched, even social harmony can lose its substance, and finally the reality of social media communication can also be a threat to broader social harmony.

\subsection{Hoax; Attack on The Harmony of Countries}

One form of threat to social harmony is hoaxes. Hoaxes are fake news that is done using communication media. The substance of hoaxes is telling lies, where this behaviour has existed since humans existed. But when a person without using the medium of communication has lied to others, then the effect of lying will result in someone being lied to. It can also be the effect of lying about others around the person who is told the lie, but in a limited environment. However, communication media hoaxes will have far greater consequences and will impact and complicate the wider social life even very broadly, destroying harmony and even putting society and the country at risk.

In the case of fake news by RatnaSarumpaet, some time ago, it was an example of the construction of the reality of social media. So, when RatnaSarumpaet told her children that her bruised face was as a result of the persecution against her, then her pictures spread on social media as news of the persecution, in addition, his silence on the reaction of the political elites regarding the persecution he wrote, led to the formation of social construction through mass media over the reality of persecution against RatnaSarumpaet, which reality lived for days in society.

In this case the construction of mass social media can build a reality hoax, which is a false news that actually does not exist. Although hoaxes are simpler when compared to the process of mass media social construction, therefore hoaxes have a "life span" in cognitive shorter than the construction of social media itself. Nevertheless, hoaxes have a powerful and widespread sporadic damage in society.

Hoaxes are one of the serious issues in the ethics of communication, especially political communication, because in addition to having an "entertainment effect", hoaxes can damage the image of people or political opponents. Therefore, the real hoax is the enemy of society and the state. All hoax news not only harms the subject of hoaxes but also attacks and undermines the ethical order (political ethics in society), even hoaxes can be a killing machine of one's character or the authority of the state. This is evident in the case of RatnaSarumpaet, the persecution hoax has been used by political opponents to attack each other. The image below is a picture of the construction of social media building hoaxes.

Picture 1: Epistemology The Social Construction of Hoax $(\mathrm{SCoH})$

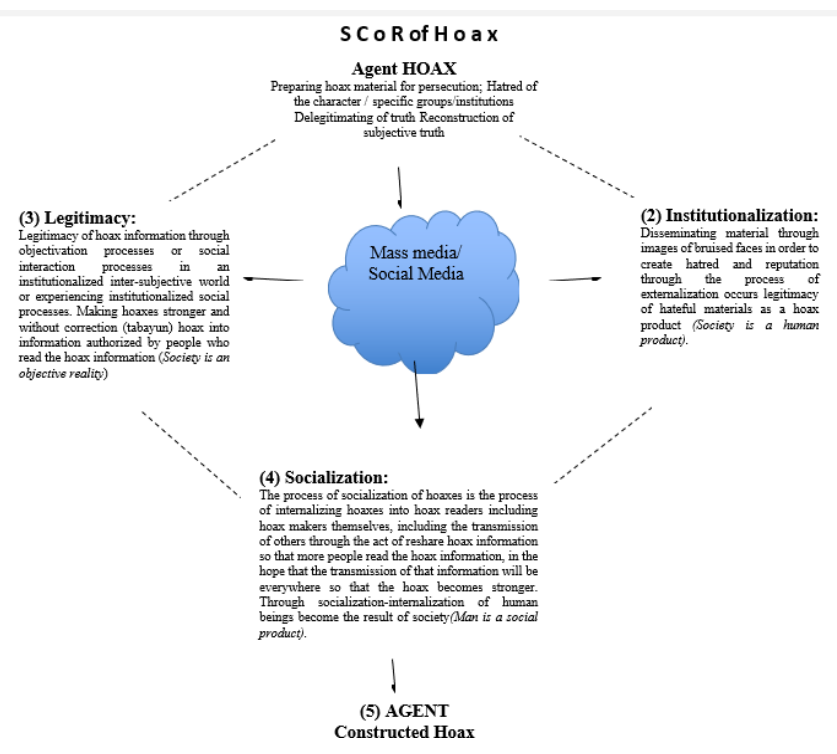

Source: Simulated from Burhan Bungin, Political Communication Imaging (2017)

People who are less aware of media literacy, then hoaxes become a medium of growing and breeding hoaxes dynamically in a wide spectrum. The hoax will attack various political groups and opponents as well as attack the most important figures, people in a particular religious group, ethnicity, or state institution through the delegitimization of truth and reconstruction of imaginary truth created by hoax producers.

The process of hoax epistemology has a simple cycle like the image above, in which it is subjectively imaginary, hoax agents prepare hoax content then spread or spread the hoax content to social media to be broadcast to everyone connected to social media as an incubator media in the institutionalization process, legitimacy and socialization and finally constructed the social image of hoaxes in everyone who reads or sees the news that is made hoax agents. 
In general hoaxes are not a matter of society in general, but most importantly hoaxes related to state power or the power of some elite groups related to the state. Because hoaxes are not particularly beneficial for personal-related issues that do not have access to power. Therefore, hoaxes are more dangerous to attack rulers or people around them. In real terms, the state is often or can be the best agent of hoaxes, because the state has all the tools of hoax production equipment, but hoaxes made by the state are always considered as something that is not "sinful". In the Suharto era, for example, all officials could use the word "secured" to eliminate someone. We all know the word secured contains the meaning of in safe. It's an example of a hoax made by the state against citizens and used for years by the Suharto regime. But if the hoax is made by citizens to criticize or attack the ruler or those around him, then it is seen as something dangerous, anti-state, anti-corruption and so on.

So really this hoax is a state problem not just a matter of society. The state considers hoaxes a threat and only countries can carry out hoaxes. While among the public often also consider hoaxes as "entertainment" to "disturb" the peace of the country or people around it.But there are also hoaxes used by people around the state's power circle to attack their neighbours, this is then considered something that must be ethically regulated while the law is difficult to prove factually. Because indeed hoaxes have a bad substance that is slandering others through the medium of communication, especially mass media and social media.

Various hoaxes have opened our eyes that communication media especially social media is the best hoax incubator that exists in society today. There is no guarantee that people in any social class will be sterile from the influence of the power of hoax social construction, even if the state will one day be contaminated with the influence of this hoax while those around power have also been the targets of netizen criticism. Imagine if some of the president's advisers were stricken with hoaxes, then advised the president to make urgent and swift actions to address the state of the country, it would be very dangerous for the safety of the country. Thus, hoaxes are a threat to the harmony of the country and the nation.

So, so powerful is the influence of this hoax that we all have no power whatsoever against it, except fortifying ourselves with media literacy. Especially information on social media must be countered by our critical power to that media. Any information obtained from mass media or social media must be recorrected. Often, information in the mass media fails to become a tool of social media Triangulation, meaning that when people get information on social media, it then confirms to television or other mass media including online media, or vice versa. But it turns out that television media, mass media and online media have also reported on this hoax event. Therefore, using our critical power, the act of stalling to think, double-checking the original source, is the best way to open the true veil of the social reality constructed by the hoax.

Berger and Lukmann (1967) explained that social reality is formed through social processes that occur in society. The social process occurs simultaneously through the social construction of reality (technology), In which social processes; institutionalization, legitimacy and socialization (ILS).

Institutionalization social process is carried out through another simultaneous process, namely externalization, objectivization and internalization (EOI). So, the construction of social reality is a simultaneous and multilayered social process through ILS-EOI. In the process of institutionalization there is the formation of patterns, rules or roles among a group of people. The process of building creation (construction) social technology takes place through 3 social processes in 3 other processes (3 in 3 ) simultaneously. Social building is a social reality that gives image to a technological identity in social relationships as well as the output of those social relationships. In the end the social reality of technology gives identity to the outcome as an image attached to it (Berger dan Luckmann, 1967).

The formation of this pattern is successful if communication technology is considered successful and relevant to meet the collective needs of the community in certain situations. So that the role and provisions that make communication technology as a structured institution in the community (Geger, 2009). For example, when technology takes over the role of man, then from then on there has also been a process of forming patterns, rules or the role of technology in the structure of human social life. For example, when robots replace Reception, the human role in that field becomes lost and replaced by machines. When drones take over the position of human-run transportation tools, human positions become unurgent in that sector, even old transportation tools become deprived of their function.

The process of institutionalization of technology (new) is successful, then this structured technology institution is legitimized or clarified with logical explanations, as a logical need, as a result of unavoidable changes. Institutions are maintained by being socialized to new members of society. Starting from one technology made, he has become a new member in the community institution. Since then, she has become considered to be able to create her social reality. $\mathrm{He}$ is socialized with his language institutions, family institutions, community institutions and others (Geger, 2009).

\section{CONCLUSION}

The social changes occurred because it triggered the new role of internet and social media application machines that dominated and replaced the power of the great current in the process of the social construction of reality as referred to by Berger and Luckmann (1967).

The substance of communication media technology as a tool of human equipment periodically has been more efficient and more sophisticated serving humans in the era of Society 5.0. The presence of communication media technology in this era becomes a more meaningful human life in front of its own creation. But behind all of that there are other social processes that are missing, which have been created in the long, simultaneous and convoluted social process that is the social reality that becomes an important part of human social life. Social reality is not only 
something that is visible but also invisible and becomes something that meaningful in social life.

In fact, that various social realities within Society 5.0 such as society, social interaction, status and roles, values and norms, social institutions, culture, social stratification, social behavior, and social change are human social realities created through the process of social construction, will disappear one by one, at least will change slowly in harmony with the exchange of social harmony in the social process.

Social harmony that is swapped or even disappeared from human life, let's say, social change in the family, because household robots will replace human life partners, this threatens family harmony and one day the social reality of the family will shift or disappear. The human population will decrease due to this new social reality as well as disrupt human social harmony as a member of society and one day man will perish. Social groups will disappear replaced with virtual groups on facebook or WhatsApp and so on because the social harmony is disturbed. It will also encourage the loss of old social values and be replaced with new social values based on social media laws.

The changing social behavior of social media users who threaten social harmony will also disturb the surrounding environment. The change in social stratification based on the number of likes is not due to science, wealth, and honor and so on and so on becomes a way of people changing their leadership style by attaching importance to social imagery as the way they influence people.

These changes disrupt social harmony in old social realities. Where there will be changes in the value system. The old values were abandoned by people, and the new values built on the logic of the industrial revolution 4.0 and communication media technology became a trend as described in Society 5.0.

The change in values and the order of social harmony is an inevitability built by capitalism with the accomplices of large companies of communication media technology makers, will dredge up the enormous profits of his creation and the production system that places man as a slave to technology and servant of capitalism

\section{REFERENCES}

[1] Burhan, B. (2018). KomunikasiPolitikPencitraan, The Social Construstion of Public Administration, Jakarta: Prenada Media.

[2] Burhan, B. (2020). Post-Qualitative, Social Research Methods, Kuantitatif-Kualitatif-Mixed Methods, Positivisme-Postpositivisme-Phenomenology-Postmodern. Filsafat, Paradigma, Teori, Metode dan Laporan. Jakarta: Prenada media.

[3] Berger, P. L. and Luckmann, T. (1967). The Social Cunstruction of Reality. London: Penguin Books.

[4] Copeland. B.J. (1993). Artificial intelligence. Diaksesdari, https://www.britannica.com/technology/artificialintelligence/ Methods- and-goals-in-AI

[5] Creswell, J.W. and Creswell, J.D. (2018). Research Design Qualitative, Quantitative, and Mixed Methods Approaches. Fith Edition, Los Angeles: Sage Publication.

[6] Hygoblog. (2016). MadaDepan Situs Berita) Media Online MulaiSuram. Diaksestanggal $28 \quad$ Julidari https://goblogbiz.wordpress.com/ 2016/05/18/masa-depansitus-berita-media-online-mulai-suram/

[7] McAfee, A., Brynjolfsson, E. (2017). Machine Platform Crowd, Harnessing Our Digital Future. New York: W.W. Norton Campany.

[8] Peristiwa. (2019). Satu Persatu Koran di Indonesia TutupUsia. Diaksestanggal 28 Julidarihttps://www.sergapreborn.id/satu-persatu-koran-diindonesia-tutup-usia/

[9] Ritzer, G., Stepnisky, J. (2017). Sociological Theory. London: Sage.

[10] Riyanto, G., (2009). Peter L. Berger, PerspekstifMetateoriPemikiran, Jakarta: LP3ES.

[11] Saldana, J. (2016). The Coding manual for Qualitative Researchers. London: Sage Publication.

[12] Salgues, B. (2018) Society 5.0 Industry of the Future, Technologies, Methods and Tools. London: ISTE Ltd.

[13] Dwiyana, D., \& Muqorobin, M. (2021). Analysis of Adi Soemarmo Solo Airport Parking Payment System. International Journal of Computer and Information System (IJCIS), 2(1), 1-3.

[14] Muryani, A. S., \& Muqorobin, M. (2020). Decision Support System Using Cloud-Based Moka Pos Application To Easy In Input In Orange Carwash Blulukan Flash N0. 110 Colomadu. International Journal of Computer and Information System (IJCIS), 1(3), 66-69.

[15] Hikmah, I. N., \& Muqorobin, M. (2020). Employee Payroll Information System On Company Web-Based Consultant Engineering Services. International Journal of Computer and Information System (IJCIS), 1(2), 27-30. 